\title{
EFEITOS DE UM EVENTO ASTRONÔMICO DE SUPERLUA NA FORMAÇÃO DE RESSACAS DO MAR NO LITORAL DO CEARÁ E SUAS ALTERAÇÕES NA MORFOLOGIA PRAIAL
}

\author{
Jailson Cavalcante Lima ${ }^{(a)}$, Ismael Furtado Pereira Lima ${ }^{(b)}$, Antônio Emanuel dos Santos Silva ${ }^{(\mathrm{c})}$, \\ Davis Pereira de Paula ${ }^{(\mathrm{d})}$ \\ (a) Centro de Ciências e Tecnologia, Universidade Estadual do Ceará, jaillsonline@gmail.com \\ (b) Centro de Ciências Exatas e Tecnologia, Universidade Estadual Vale do Acaraú, limaifp@live.com \\ (c) Centro de Ciências e Tecnologia, Universidade Estadual do Ceará, antonioemanuel2912@ gmail.com \\ (d) Centro de Ciências e Tecnologia, Universidade Estadual do Ceará, PROPGEO/UECE, MAG/UVA \\ davis.paula@uece.br
}

\section{Eixo: DINÂMICA E GESTÃO DE ZONAS COSTEIRAS}

\begin{abstract}
Resumo
Este trabalho avaliou os efeitos do fenômeno de superlua na formação de um evento de ressaca do mar no litoral do Ceará, tendo como estudo de caso, as alterações morfológicas causadas na Praia do Icaraí, Caucaia-CE. Para a avaliação foram monitorados 3 perfis de praia ao longo de 4 dias (14/11/2016 a 17/11/2016) de ocorrência do evento, os perfis foram levantados com auxílio de uma estação total. A partir dos dados adquiridos foi observado que as ressacas do mar não induziram alterações morfológicas significativas na Praia do Icaraí e tão pouco provocou algum tipo de dano aos equipamentos urbanos ali instalados, contrariando a lógica de um evento apenas destrutivo.
\end{abstract}

Palavras chave: Litoral, Ressaca do mar, Praia do Icaraí.

\section{Introdução}

A zona costeira é uma faixa de transição, entre o continente e o oceano, dotada de uma diversidade de ambientes submetidos a influência de forçantes naturais (e.g. ondas, marés, correntes marinhas e vento) e atividades humanas (e.g. turismo, veraneio e indústria) que são responsáveis por induzirem transformações na paisagem litorânea.

Paula (2012) e Fernandes et al. (2015) destacaram que as ressacas do mar são responsáveis por promoverem rápidas transformações na fisiografia das praias, principalmente, quando da atuação conjunta de eventos astronômicos e/ou meteorológicos que provoquem a sobreelevação momentânea do nível do mar, como é o caso dos eventos de superlua. Este evento ocorre quando a lua fica mais próxima da terra, podendo ser potencializado em momentos de perigeu, isto é, quando o sol também está mais próximo.

De acordo com Paula et al. (2015), as ressacas do mar são resultantes do empilhamento da massa de água junto a costa (wave set-up), provocando o galgamento das estruturas naturais e antrópicas. No estado do 
Ceará, as ressacas podem ser induzidas por forçantes únicas (e.g. ondas) ou associadas (e.g. ondas e maré). Decerto é que um evento de superlua, como observado em novembro/16, pode induzir a formação de uma ressaca do mar. O seu potencial energético dependerá da sua associação com outras forçantes naturais.

Deste modo, este estudo tem por objetivo avaliar os efeitos do fenômeno de superlua na formação de um evento de ressaca do mar no litoral do Ceará, tendo como estudo de caso, as alterações morfológicas causadas na Praia do Icaraí, localizada no litoral de Caucaia-CE, durante o evento ocorrido entre os dias de 14 e 17 de novembro/16.

\section{Materiais e Métodos}

A praia do Icaraí está localizada no município de Caucaia (Figura 1), no litoral da Região Metropolitana de Fortaleza (RMF), distando aproximadamente $20 \mathrm{~km}$ de Fortaleza, capital do Ceará. (IPECE, 2015). Trata-se de um dos principais núcleos de erosão costeira do Estado, em que o avanço do mar tem provocado o recuo da linha de costa e a destruição do patrimônio edificado.

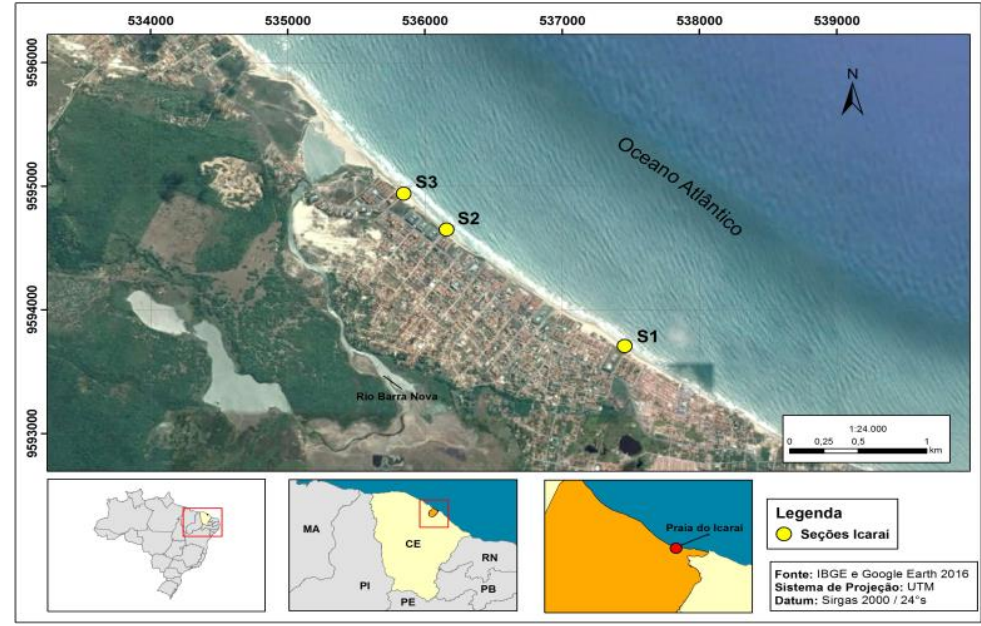

Figura 1 - Localização da área de estudo, a Praia do Icaraí (Caucaia, Ceará).

No intuito de avaliar as alterações morfológicas induzidas pela ressaca do mar de índole astronômica, foram monitorados 3 perfis de praia ao longo de 4 dias (14/11/2016 a 17/11/2016) de ocorrência do evento. Para efeitos de comparação, foi utilizado o perfil de pré-ressaca do dia 19/09/2016. A aquisição dos dados da topografia da praia obedeceu a sistemática clássica desenvolvida por Birkmeier (1981). Todos os perfis estão referenciados ao zero hidrográfico da Diretoria de Hidrografia e Navegação - DHN e foram reocupados diariamente no período de baixa-mar. Os perfis foram levantados com auxílio de uma estação total e de um prisma topográfico. 
Os perfis foram demarcados e georreferenciados previamente com o auxílio de um Differential Global Positioning System (DGPS), ao logo de um trecho de aproximadamente $2 \mathrm{~km}$. Para a realização do estudo também foram monitorados os parâmetros de ondas, maré e ventos. Os dados de ondas e ventos foram adquiridos no site Surfguru, que adota a previsão de ondas a partir do modelo Wavewatch desenvolvido nos laboratórios do Centers for Environmental Prediction - NOAA/NCEP, além de dados de marés adquirido no site da Diretoria de Hidrografia e Navegação (DHN).

\section{Resultados}

\section{Condições de agitação marítima}

O evento de ressaca do mar observado foi induzido por um evento astronômico, no caso, a ocorrência da superlua. Nesse evento, não houve atuação significativa das ondas, apenas no primeiro dia houve incidências de ondas com um pouco mais de $1 \mathrm{~m}$ de altura $(\mathrm{Hs})$, com período médio de $10 \mathrm{~s}$ e direção E/SE. Nos demais dias, o Hs ficou abaixo disso. Já com relação a maré, a amplitude nos dois primeiros dias do evento chegou a $3,3 \mathrm{~m}$, sendo que nos dias que se seguiram foi de 2,9 m. Enquanto que, a sobreelevação máxima momentânea do nível do mar registrada no marégrafo do Porto do Pecém foi de 15 $\mathrm{cm}$.

\section{Seção 1 - Área de dunas antropizadas}

Na seção 1, as maiores variações morfológicas foram observadas na parte submersa do perfil da praia (entre 70 e 130 metros de distância do RN), assim mesmo, não passaram de 1 m vertical (Figura 2). Outra alteração perceptível foi registrada na base da duna frontal, onde existe uma escadaria de acesso à praia que foi danificada pelas ondas de ressaca do mar no primeiro dia do evento. Nesse setor houve uma diminuição de quase $1 \mathrm{~m}$ na coluna vertical de areia, resultando nesse dano. De modo geral, não houve uma variação significativa na largura da praia que possa ser atribuída a um forte processo de erosão costeira induzido pelo evento de ressaca do mar. Muito pelo contrário, em alguns momentos do evento houve um recobrimento geral do perfil praial.

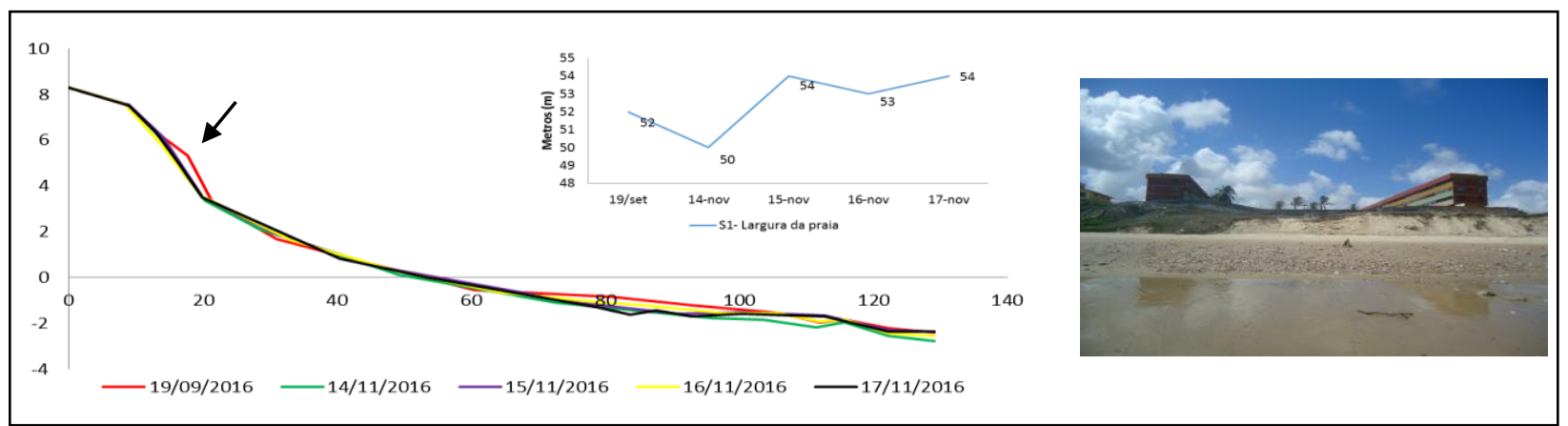

Figura 2 - Variação morfológica da seção 1 da praia do Icaraí (A e C) com indicação de mudanças na largura da praia (B). 
XVII Simpósio Brasileiro de Geografia Fisica Aplicada

I Congresso Nacional

de Geografia Física
OS DESAFIOS DA GEOGRAFIA FÍSICA NA FRONTEIRA DO CONHECIMENTO

Instituto de Geociências - Unicamp

Campinas - SP

28 de Junho à 02 de Julho de 2017

\section{Seção 2 - Área com presença de obras costeiras}

A seção 2 (Figura 3), limitada por um enrocamentos de pedras e restos construtivos de uma antiga obra, apresentou algumas variações morfológicas importantes, especialmente, na alta praia e no estirâncio inferior, onde houve uma diminuição de mais de $2 \mathrm{~m}$ verticais no pacote sedimentar durante o evento de ressaca do mar. A praia apresentou nesse trecho um recuo significativo de $24 \mathrm{~m}$ de largura (Figura 3B) após a atuação do primeiro dia de evento de ressacas do mar, na qual houve a remoção de um grande volume de sedimentos, entre as distâncias de 45 e 97 metros (Figura 3A). Este fato pode ser justificado pela atuação de ondas de aproximadamente 1,0 m de altura e a grande amplitude de maré do dia, ultrapassando os 3,0 m. Nesse setor, os efeitos do evento de ressaca do mar são mais notórios se comparado a seção 1 .

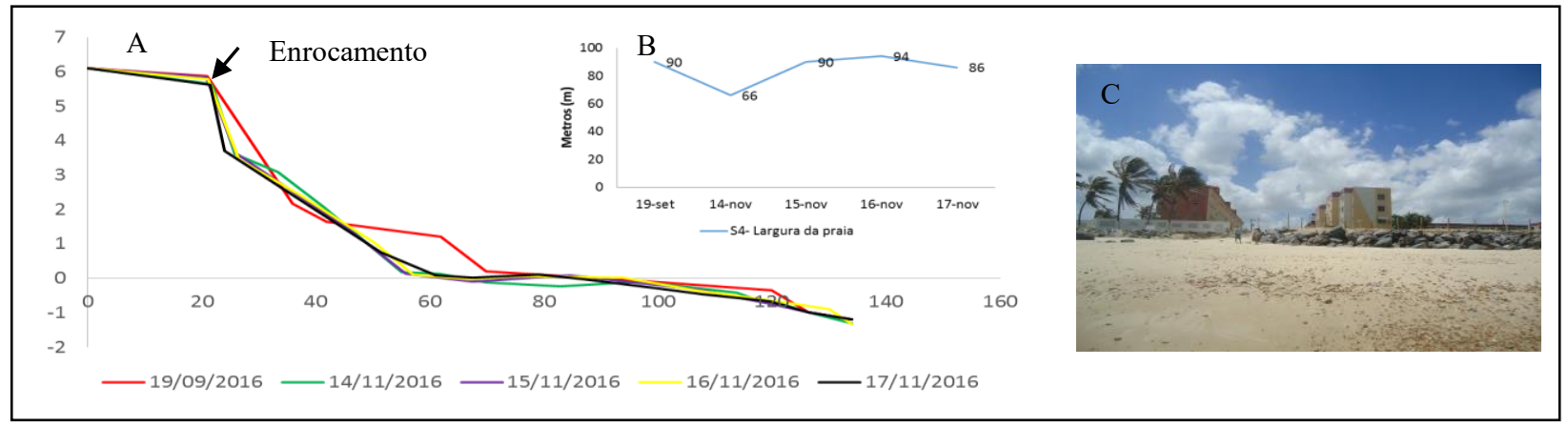

Figura 3 - Variação morfológica da seção 2 da praia do Icaraí (A e C) com indicação de mudanças na largura da

\section{Seção 3 - Área com dunas naturais} praia $(B)$.

Transversal a uma duna natural (Figura 4C), a seção 5 apresentou variações morfológicas induzidas pelo evento de ressaca do mar e pela ação dos ventos fortes no litoral do Ceará no segundo semestre do ano. Observando o perfil de pré-ressaca e os de ressaca é nítido que houve uma diminuição na altura da crista da duna provocado pelo vento, pois nesse trecho costeiro não há galgamento oceânico (Overwash). Também houve um ligeiro recuo da base da duna induzido pelo alcance máximo das ondas de ressaca do mar, que atingiram a cota de 4,5 m. Esse material foi depositado ao longo do perfil da praia, aumentando o volume do pacote sedimentar em mais de 1,0 m vertical de areia, o que resultou num aumento da largura da praia em 3 m, em média, entre os dias 14/11/16 e 17/11/16. 


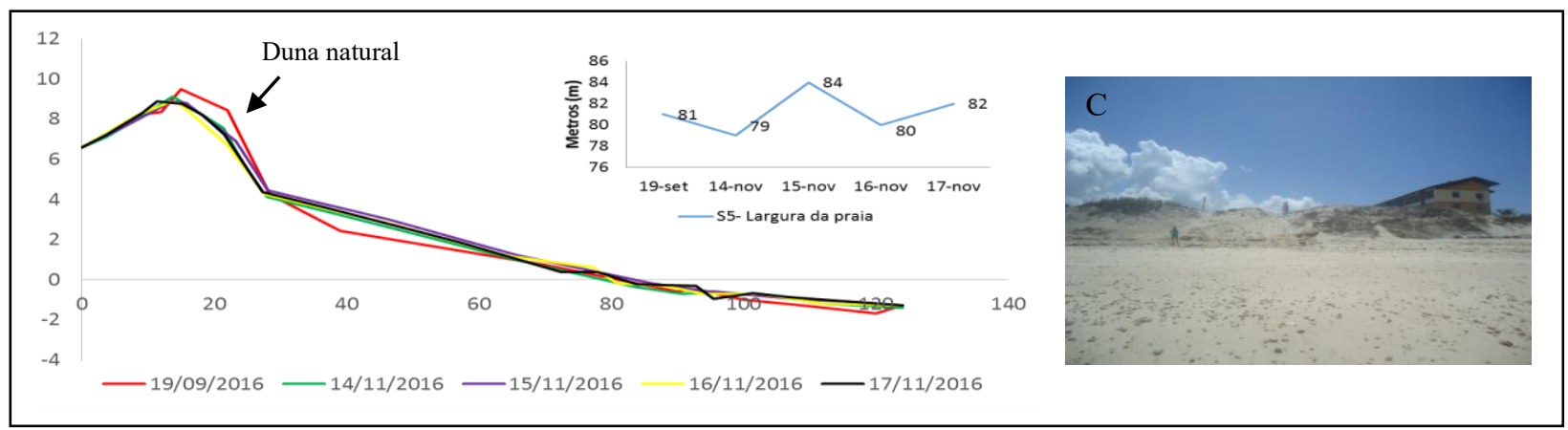

Figura 4 - Variação morfológica da seção 3 da praia do Icaraí (A e C) com indicação de mudanças na largura da praia (B).

\section{Conclusão}

O evento de ressaca do mar observado não induziu alterações morfológicas significativas na Praia do Icaraí e tão pouco provocou algum tipo de dano aos equipamentos urbanos ali instalados. Como já destacado por Paula et al. (2015), as ressacas induzidas apenas por marés não são tão destrutivas, isso ficou comprovado nos resultados dos perfis de praia. Outra importante observação foi que em alguns momentos do evento houve deposição de areias ao longo do perfil, contrariando a lógica de um evento apenas destrutivo.

Como já esperado, os perfis que estão limitados por dunas apresentaram um comportamento mais similar, ficando evidente o recobrimento do perfil por areias transportadas da alta praia em direção ao estirâncio médio, especialmente na seção 3. Claro, que essa relação depende da configuração (Setup) da agitação marítima do dia observado. No setor em que o perfil é limitado por uma estrutura rígida de proteção houve uma redução generalizada das cotas topográficas da praia, quando comprado com o perfil pré-ressaca do mar, mas nada que indique um processo de erosão consolidado. Nessa perspectiva, é possível destacar que os estudos voltados a apreensão do fenômeno de ressacas do mar e seus impactos devem ser associados aos programas de gestão costeira.

\section{Agradecimentos}

Ao CNPq pelo auxílio financeiro ao projeto "Impactos costeiros no litoral de Caucaia (Ceará, Brasil) induzidos pelas obras costeiras construídas a sotamar e pelas ressacas do mar" (Processo: 483811/2013-2). À FUNCAP pela concessão da bolsa de iniciação científica. 


\section{REFERÊNCIAS}

BIRKEMEIER, W. A. Fast Accurate Two-Person Beach Survey. 22 p., Coastal Engineering Technical Aid 81-11. U.S Army Engineer Waterways Experiment Station. Coastal Engineering Research Center, Vicksburg, Mississippi, USA, 1981.

IPECE - Instituto de Pesquisa e Estratégia Econômica do Ceará. Perfil básico municipal de Caucaia. 2015. 18 p.

FERNANDEZ, G. B; MALUF, V; BULHÕES, E. M; ROCHA, T. B; PEREIRA, T. G; FILHO, S. O; Impactos morfológicos e resiliência das praias no litoral do Rio de Janeiro: referência especial a morfodinâmica praial. In: PAULA, D. P; DIAS, J. A; Ressacas do mar: temporais e gestão costeira. Fortaleza: Premius. 2015. Seção 3, cap. 2 , p. 277-329.

PAULA, D. P. Análise dos riscos de erosão costeira no litoral de Fortaleza em função da vulnerabilidade aos processos geogênicos e antropogênicos. Tese de doutorado, Universidade do Algarve, Faculdade de ciências do mar, 2012. $335 \mathrm{p}$.

PAULA, D. P; MORAIS, J. O; FERREIRA, O; DIAS, J. A. Análise histórica das ressacas do mar no litoral de Fortaleza (Ceará, Brasil): origem, características e impactos. In: PAULA, D. P; DIAS, J. A. Ressacas do mar: temporais e gestão costeira. Fortaleza: Premius. 2015. Seção 2, cap. 2, p. 173-201. 